\title{
As Gravuras Japonesas, de John G. Fletcher
}

\author{
Anderson Lucarezi \\ Lucas Zaparolli de Agustini
}

\section{John Gould Fletcher}

John Gould Fletcher (1886-1950) nasceu em Little Rock, Arkansas, no seio de uma família abastada, o que lhe possibilitou estudar em Harvard. Com a morte do pai, em 1906, deixou a universidade para viver de herança e empreendeu uma longa viagem para a Europa, acabando por estabelecer-se em Londres, onde publicou, em 1913, cinco livros às próprias custas. Nessa época, tendo conhecido Ezra Pound, tornou-se ativo difusor da corrente estética do Imagismo.

Em 1915, alcançou notoriedade entre os poetas americanos com a publicação de Irradiations: Sand and Spray. No mesmo ano, após ter visto uma exposição de pintura japonesa em Boston, no Museum of Fine Arts, passou a refletir a respeito de uma forma de mesclar a tradição oriental com a ocidental. A respeito dessa tentativa, vale lembrar Edna B. Stephens, que afirma que o intuito do poeta era "fundir o entendimento intuitivo do Oriente com as energias explosivas da América".

Dessa exposição inspiradora surgem os "quase" haicais aqui traduzidos, pertencentes ao livro Japanese Prints, de 1918. Vale pontuar que mesmo antes disso Fletcher já demonstrava interesse pelo Oriente, como atesta o título Goblins and Pagodas, de seu livro de 1916, que indica mescla de referências ocidentais (goblins, figuras mitológicas nórdicas) com orientais (templos pagodas). Foi, no entanto, no Budismo - intensivamente trabalhado nos haicais a partir de Bashô - que Fletcher achou a via para compor seus próprios textos "japonizados" e de começar a harmonizar Oriente e Ocidente, sempre lançando mão do misticismo, elemento

1 STEPHENS, Edna B. 1967. John Gould Fletcher. Twayne Publishers. New York. p. 57. 
recorrente em toda a sua obra. Em Parables (1925), por exemplo, dialoga com o Hinduísmo. Já em South Star (1941), apresenta uma atitude anti-industrialista e uma defesa do primitivismo, da quietude taoista e da doutrina confucionista do homem superior, elementos que serão fundidos poeticamente na figura do estado do Arkansas da época dos pioneiros do oeste.

Fletcher retornou para o Arkansas em 1933, casou-se, em 1936, com a escritora Charlie May Simon e ganhou, em 1939, com a publicação de Selected Poems, o Prêmio Pulitzer. Embora ainda escrevesse poesia, a depressão levou-o a se matar por afogamento, em 1950.

\section{As Gravuras Japonesas}

Em Japanese Prints, Fletcher buscou produzir em língua inglesa os chamados hokkus (transliteração da palavra japonesa 発句, que em português adquiriu a grafia "haikai" e, após a queda do K na reforma ortográfica de 1943, "haicai”).

Os haicais tradicionais adotam um esquema de três versos com 5 - 7 - 5 sílabas, respectivamente, e possuem ao menos uma palavra que aluda a uma estação do ano. No caso de Fletcher, a forma japonesa foi flexibilizada, assim como ocorreu no Brasil com o trabalho de Paulo Leminski e Alice Ruiz. Na introdução ao livro, o autor diz que "não se pode escrever bons haicais em inglês. O que temos de seguir não é a forma, mas o espírito".

Nos poemas em questão aparece o imaginário do Japão do período Edo (1603-1868), repleto de cerejeiras, espadachins e cortesãs em quimonos que tremulam ao vento - imagens típicas das gravuras da época, chamadas Ukiyo-ê, nome que significa, literalmente, "retratos do mundo flutuante", alusão à atmosfera "hedonista" surgida com a nova capital do país, Edo (atual Tóquio), e suas diversões.

Fletcher, entretanto, afirma na introdução que "quanto aos próprios poemas, não são em alguns casos completamente japoneses, mas todos ilustram algo do encanto que eu encontrei na arte e poesia japonesas."

É importante destacar que o interesse de Fletcher pela poesia e pela cultura do Oriente não é um fato isolado. Três anos antes da publicação de Japanese Prints, Ezra Pound (1885-1972) lançava Cathay, livro que recriou para a modernidade a poesia chinesa antiga ao apresentar "quase-traduções" baseadas nos manuscritos do sinólogo Ernest Fenollosa. Em 1916, Pound trouxe a público Lustra, em que explorava a brevidade do haicai. No mesmo ano, E. E. Cummings (1894-1962) publicava um poema chamado Hokku no periódico The Harvard Monthly. Em 
1921, Amy Lowell (1874-1925) publicava suas próprias experiências com haicais. Wallace Stevens (1979-1955), em 1923, apresentava Harmonium, em que constam alguns poemas imbuídos da brevidade e da atmosfera do haicai, como é o caso de Thirteen Ways of Looking at a Blackbird.

Vê-se, então, certa vontade de revitalização da prática poética ocidental através do contato com elementos orientais. Esse interesse das primeiras décadas do século XX, no entanto, não foi pioneiro, já que a incorporação de elementos orientais pelo Ocidente remonta pelo menos ao século XVI, com o advento das grandes descobertas marítimas (na verdade, tem havido intercâmbio desde a Antiguidade). Houve diálogo com a arte africana e asiática durante todos os séculos subsequentes, mas, no caso do extremo Oriente - do Japão, em especial - o diálogo avivou-se mais a partir da segunda metáde do século XIX, quando o governo japonês retomou contato com o mundo externo, já que tinha ficado por mais de duzentos anos sob um regime de fechamento às relações internacionais.

Com a abertura japonesa, a partir de meados da década de 1850, e com as exposições internacionais da segunda metade do século, que ajudaram a divulgar a cultura oriental no Ocidente, chegou à Europa e a outras partes do mundo um grande fluxo de elementos nipônicos, como cerâmicas e as próprias Ukiyo-ê, o que engendrou uma tendência intitulada Japonismo. Sob este pano de fundo, surgiram, no campo das letras, várias manifestações que dialogaram com o Extremo Oriente, sendo que alguns exemplos relevantes são, em língua portuguesa: Antonio Feijó (1859-1917), autor de Cancioneiro Chinês (1890), Camilo Pessanha (1867-1926), que deixou sua poesia se imbuir das referências da China, além de ter sido tradutor de elegias chinesas, e Wenceslau de Morais (1854-1929), que escreveu relatos sobre o Japão e, já no século XX, traduziu haicais para o português. No campo das letras em língua inglesa, destacam-se os trabalhos referentes a língua, literatura e história chinesas e japonesas escritos por Herbert Allen Giles (1845-1935) e Ernest Fenollosa (1854-1908). No âmbito das artes plásticas, houve a incorporação de elementos das Ukijo-ê pelo americano James Abbott McNeill Whistler (1834-1903) e pelos pintores impressionistas e pós-impressionistas europeus, sendo que dois deles são Vincent van Gogh (1853-1890), que tinha sua própria coleção de gravuras, e Paul Gauguin (1848-1903), não por acaso biografado por Fletcher.

O gosto pelo Oriente não foi, tampouco, um interesse que acabou no começo do século XX. Uma das vanguardas poéticas dos anos de 1950, a Poesia Concreta brasileira desenvolveu um intenso estudo da mentalidade oriental, principalmente do ideograma, cuja lógica foi incorporada à prática escritural dos poetas pertencentes ao movimento. Em Portugal, autores como Herberto Helder 
(1930-2015) e Ana Hatherly (1929-2015) dialogaram com o Japão através da caligrafia e da recriação do koan, gênero textual tradicional. No mundo anglófono, vale citar o britânico Reginald Horace Blyth (1898-1964), tradutor de haicais, e os norte-americanos Jack Kerouac (1922-1969), autor de vários haicais copilados após sua morte, e Jerome Rothenberg (1931), que publicou traduções do chinês e do japonês, além de ter escrito pelo menos um livro de poemas que dialoga diretamente com o Japão, The Seven Hells of Jigoku Zoshi (1962).

\section{Comentários sobre a traduçáo}

Em relação à tradução, procuramos nos ater aos princípios da própria poesia imagista, que ainda ecoa nestes poemas. $\mathrm{O}$ uso de um léxico mais comum e coloquial, em detrimento dos vocábulos mais eruditos, era um pressuposto imagista que visava o trato direto da imagem, evitando, assim, empolamentos desnecessários. Nesse sentido, por exemplo, optamos sempre pela próclise, já que soa mais comum no português brasileiro, chegando a soluções como: "O sol a se pôr as acerta em cheio".

Em outros momentos, apostamos em soluções inventivas, como foi o caso de tradução de "Emperor's jewel-trees" como "pés-de-joias do imperador", na qual se observa mantida a estrutura composta do substantivo, a hifenização, assim como a própria imagem de uma frutificação pródiga. Entretanto, tais soluções inventivas não desgrudam em demasia do conteúdo semântico expresso no original. Outro ponto relevante é a tradução de robes, termo incorporado ao português que pode ser traduzido aceitavelmente por "robe", mas que nestas Gravuras Japonesas foi traduzido por "quimono", vocábulo de etimologia japonesa totalmente assimilado ao português do Brasil, país que abriga a maior comunidade nipônica fora do Japão.

Já no que diz respeito à tradução da sonoridade, um bom exemplo seria o verso "The soft sigh of the wind through silken garments", com seu ritmo marcado e impregnado de sibilantes e de ecos de algumas dentais, como a dar o efeito onomatopaico do próprio vento passando entre as vestimentas de seda, que foi traduzido por "O suspiro suave do vento entre vestes de seda", cuja intenção tradutória foi a de manter as características presentes na sonoridade do original, a fim de sugerir similares efeitos imagéticos oriundos de similares sonoridades.

A ideia, enfim, é chegar a uma recriação integral de Japanese Prints para a língua portuguesa, projeto já concluído. A opção pela tradução integral se revela interessante a partir do momento em que muitas vezes o leitor brasileiro só vem a conhecer obras de poetas através da forma fragmentada das coletâneas. Traduzir 
livros inteiros é uma forma de expor toda a complexidade do pensamento e da escritura que determinado autor desenvolveu durante certo período.

No caso do pouco conhecimento entre nós de John G. Fletcher, a intenção desta tradução é dar visibilidade a esse escritor de língua inglesa para que sua obra possa enriquecer o cenário atual da literatura brasileira.

\section{Tradução}

\section{LOVERS EMBRACING}

Force and yielding meet together:

An attack is half repulsed.

Shafts of broken sunlight dissolving

Convolutions of torpid cloud.

\section{AMANTES ABRAÇADOS}

Força e entrega agindo em conjunto:

Um golpe é quase repelido.

Raios de sol rompidos dissipam

Convoluções de nuvem tórpida. 


\section{A PICNIC UNDER THE CHERRY TREES}

The boat drifts to rest

Under the outward spraying branches.

There is faint sound of quavering strings,

The reedy murmurs of a flute,

The soft sigh of the wind through silken garments;

All these are mingled

With the breeze that drifts away,

Filled with thin petals of cherry blossom,

Like tinkling laughter dancing away in sunlight.

\section{UM PIQUENIQUE SOB AS CEREJEIRAS}

O barco desliza pra descansar

Sob os aparentes galhos molhados.

Há sons fracos de cordas trêmulas,

Os murmúrios frágeis de uma flauta,

O suspiro suave do vento entre vestes de seda;

Tudo isto está mesclado

Com a brisa que desvanece,

Repleta de finas pétalas de flor de cerejeira,

Como tinir de riso que dança ao longe à luz do sol. 


\section{COURT LADY STANDING UNDER A PLUM TREE}

Autumn winds roll through the dry leaves

On her garments;

Autumn birds shiver

Athwart star-hung skies.

Under the blossoming plum-tree,

She expresses the pilgrimage

Of grey souls passing,

Athwart love's scarlet maples

To the ash-strewn summit of death.

\section{CORTESÃ SOB UMA AMEIXEIRA}

Ventos de outono vão pelas folhas secas

Às vestes dela;

Aves outonais tremem

Através do céu pego de estrelas.

Sob a ameixeira em flor,

Ela expressa a peregrinação

de almas grises que passam,

Através dos bordos escarlates do amor

Até o pico da morte, palmilhado de cinzas. 
134 Anderson Lucarezi e Lucas Zaparolli de Agustini. As Gravuras Japonesas, de John G. Fletcher

AN OIRAN AND HER KAMUSO

Gilded hummingbirds are whizzing

Through the palace garden,

Deceived by the jade petals

Of the Emperor's jewel-trees.

UMA OIRAN E SEU KAMUSO

Colibris dourados estão zunindo

Através do jardim do palácio,

Iludidos pelas pétalas de jade

Dos pés-de-joias do Imperador. 


\section{A WOMAN IN WINTER COSTUME}

She is like the great rains

That fall over the earth in winter-time.

Wave on wave her heavy robes collapse

In green torrents

Lashed with slaty foam.

Downward the sun strikes amid them

And enkindles a lone flower;

A violet iris standing yet in seething pools of grey.

\section{UMA MULHER EM TRAJES DE INVERNO}

Ela é como os temporais

Que caem sobre a terra no inverno.

Onda sobre onda, seu quimono pesado colapsa

Em torrentes verdes

Açoitadas por espumas de ardósia.

O sol a se pôr as acerta em cheio

E acende uma flor solitária;

Íris de cor violeta nas poças ferventes de cinza. 


\section{THE CLOUDS}

Although there was no sound in all the house,

I could not forbear listening for the cry of those long white rippling waves

Dragging up their strength to break on the sullen beach of the sky.

\section{AS NUVENS}

Ainda que não houvesse som na casa toda,

Não pude deixar de ouvir o clamor daquelas longas e oscilantes ondas brancas

Evocando suas forças pra quebrar na praia soturna do céu.

\section{THE HEAVENLY POETESS}

In their bark of bamboo reeds

The heavenly poetesses

Float across the sky.

Poems are falling from them

Swift as the wind that shakes the lance-like bamboo leaves;

The stars close around like bubbles

Stirred by the silver oars of poems passing.

\section{AS POETISAS CELESTIAIS}

Em sua barca de canas de bambu

As poetisas celestiais

Flutuam através do céu.

Poemas estão caindo delas

Velozes como o vento que balança as lâminas das folhas de bambu;

As estrelas se fecham como bolhas

Movidas pelos remos de prata de poemas que passam. 


\section{Referências}

AYSCOUGHT, Florence; LOWELL, Amy. 1921. Fir-Flower Tablets. Houghton Mifflin Company / The Riverside Cambridge Press. Boston / Nova Iorque.

BASHO; MARSICANO, Alberto (trad.); TAKENAKA, Kimi (trad.). 2008. Trilha Estreita ao Confim. Iluminuras. São Paulo.

CAMPOS, Haroldo (org.). 2000. Ideograma: lógica, poesia, linguagem. Edusp. São Paulo.

FICKE, Arthur Davison. 1917. Chats on Japanese Prints. 1915. T. Fisher Unwin Ltd. Londres

FLETCHER, John Gould. 1918. Japanese Prints. The Four Seas Press. Boston. . 1916. Goblins and Pagodas. Houghton Mifflin Company. Boston / Nova Iorque.

. 1915. Irradiations: Sand and Spray. Houghton Mifflin Company / The Riverside

Cambridge Press. Boston / Nova Iorque.

POUND, Ezra. 2003. Poems and Translations. The Library of America. Nova Iorque.

STEPHENS, Edna B. 1967. John Gould Fletcher. Twayne Publishers. Nova Iorque.

TEIXEIRA, Claudio Alexandre de Barros. 2014. A Recepção da Poesia Japonesa em Portugal. Tese não publicada. São Paulo. 